\title{
A CRISE POLÍTICA E ECONÔMICA NO BRASIL: \\ Uma análise de conjuntura sob a ótica da opinião pública nos membros \\ plenos do Mercosul.
}

\section{Ana Clara Lugão ${ }^{1}$}

\section{Resumo}

Esta análise de conjuntura oferece um retrato retrospectivo da crise política e econômica enfrentada pelo governo brasileiro no mês de abertura do processo de impeachment contra a presidente Dilma Rousseff em abril de 2015, tal como avaliado sob a ótica da opinião pública no Estados membros plenos do Mercosul: Argentina, Paraguai, Uruguai e Venezuela.

Palavras-chave: Impeachment - Crise - Brasil - Argentina - Paraguai - Uruguai - Venezuela - Mercosul

\section{Introdução}

A crise política que é enfrentada pelo Brasil tem sua origem em diferentes fatores que são atravessados por uma insatisfação popular, que o sustenta e acentua. Embora esta seja construída internamente, faz-se importante apontar as suas duas facetas: a doméstica e a internacional. No campo doméstico, a crise está associada à recessão econômica, à desigualdade social e à disputa política partidária. Esses três fatores podem ser associados à paralização do Estado brasileiro, agravando as consequências da atual conjuntura, que resultou no processo de impeachment da presidente Dilma Rousseff. No nível internacional, a crise reflete, de certo modo, o desgaste da imagem do Brasil como país emergente e, sobretudo, a sua liderança da América Latina através do seu papel desempenhado no Mercosul.

A presente análise de conjuntura se concentrará, sobretudo, no campo internacional, buscando apresentar as tendências de percepção ${ }^{2}$ acerca do processo de impeach-

\footnotetext{
${ }^{1}$ Aluna de graduação em Relações Internacionais pela Pontifícia Universidade Católica do Rio de Janeiro.

${ }^{2}$ Aqui, a percepção dos jornais será identificada através da análise de notícias, artigos de opinião e editorias. Assim, uma ressalva deve ser feita: a percepção do jornal não deve ser entendida, necessariamente, como opinião. A percepção é o passo anterior à opinião e está associada ao modo como se apreendem e se organizam as informações.
} 
ment $^{3}$ brasileiro e sua legitimidade observadas a partir de jornais de grande circulação dos membros plenos do bloco regional: Argentina, Paraguai, Uruguai e Venezuela. Reconhecendo a dificuldade da seleção dos jornais para representar o campo midiático de cada país, optou-se pelo critério de maior circulação, peso político e acessibilidade ${ }^{4}$ para a escolha dos jornais. Foi levado em consideração também a posição política dos jornais, buscando contrastar as diferentes visões, quando possível. Desse modo, o recorte dado reflete a tentativa de apresentar as diferentes narrativas e percepções acerca da legitimidade do impeachment de Rousseff.

Outra contribuição que a presente análise buscará apresentar é a relação entre a percepção da mídia e a política externa de cada país. Assim, serão analisadas as continuidades e descontinuidades entre as percepções dos jornais e dos Estados membros do Mercosul e de como estas se influenciam.

Frente a isso, uma primeira colocação deve ser feita: o Estado não deve ser compreendido como um ator homogêneo. Aqui, o Estado será entendido nos termos que Milner propõe: “o Estado não é um ator unitário, ou seja, eles não são estritamente hierárquicos, mas poliáquicos, composto por atores com diferentes preferências, que compartilham o poder sobre o processo de tomada de decisão" (MILNER, 1997, p.11).

Diante da definição de Estado proposta, é possível afirmar que a mídia representa um importante ator no aparato estatal, na medida em que é capaz de influenciar e construir a opinião pública, que possui importante influência nas decisões dos Estados democráticos. De acordo com Bobbio, a opinião pública é

uma opinião sobre assuntos que dizem respeito à nação ou a outro agregado
social, expressa de maneira livre por homens que estão fora do governo, mas
que reclamam o direito de que suas opiniões possam influenciar ou determi-
nar ações governamentais. (BOBBIO, 1998, apud, VESTENA, s.d., p.11-12).

A opinião pública, no entanto, não deve ser entendida aqui como algo dado, mas construído. Bourdieu contribui para pensar essa construção quando coloca que não há uma opinião pública, mas opiniões mobilizadas dentro de um sistema de interesses (VESTENA, s.d., p.13). A mídia, dentro desse contexto, é uma importante ferramenta

\footnotetext{
${ }^{3}$ A análise se centrará no processo e desfecho do impeachment, uma vez que este se apresenta, de certo modo, como o principal elemento sintetizador da crise política brasileira.

${ }^{4}$ Para a análise, foram buscados dois jornais de maior circulação e peso político de cada país em questão. No entanto, a escolha também foi pautada pela acessibilidade ao histórico de conteúdo dos jornais disponíveis na internet. Assim, os jornais selecionados da Argentina são o Clarín e La Nación; do Paraguai são o ABC Color e Hoy; do Uruguai são El Observador e El País; e, por fim, os da Venezuela são o Correo del Orinoco e El Nacional.
} 
para mobilizar os grupos de pressão, que por sua vez, buscam influenciar as ações do governo, inclusive quando se trata de política externa.

A influência da opinião pública sobre as decisões políticas do país pode ser compreendida através da existência de uma poliarquia. Esta não atribui o poder de decisão somente ao executivo, mas compreende que escolhas políticas são resultado de jogos estratégicos entre os atores internos (MILNER, 1997, p.14). Assim, entender o papel de agência da mídia sobre a política externa é de grande importância para compreender o alinhamento ou não alinhamento entre as percepções da imprensa e a política externa de cada país e quais são os interesses envolvidos.

A análise se traduz, nesse sentido, em um esforço para compreender futuramente quais serão as possíveis consequências do atual momento político brasileiro, percebido a partir das mídias selecionadas, para as relações futuras do Brasil com seus parceiros no Mercosul. Para tanto, ela oferece um retrato do mês de abril, período que se desenrolou o processo de impeachment da presidente Dilma Rousseff, e o momento posterior ao desfecho do processo, com a aprovação da destituição pelo Senado brasileiro.

No que tange a relação entre o Brasil e seus parceiros do Mercosul, deve-se destacar as consequências do aprofundamento da crise política brasileira, que possuem importantes impactos socioeconômicos nos países vizinhos. O papel de liderança do Brasil, cuja responsabilidade é conduzir e garantir a sobrevivência do bloco regional ${ }^{5}$ entra em risco quando a realidade apresenta a falta de administração e coesão interna. A partir dessa perspectiva, poderá se observar a preocupação dos vizinhos parceiros com a crise brasileira, uma vez que esta sugere uma possível perda da liderança brasileira e sua força política na região.

Dentro desse contexto, o ano de 2014 foi fundamental para a consolidação da crise no Brasil. A vitória de Dilma Rousseff para a presidência, dentro de um quadro político polarizado, deu início a um período de grandes contestações políticas a respeito da legitimidade para governar o país. A reeleição de Rousseff, que se deu de forma acirrada nas urnas com $51,68 \%$ dos votos, passou a simbolizar, sobretudo no Congresso Nacional, a falta de representatividade da população, que já começava a se mobilizar,

\footnotetext{
${ }^{5}$ MOREIRA, Vagner Rangel; MIRANDA, Gabriel Vinicius Mamed de. O papel do Brasil no MERCOSUL. In: Âmbito Jurídico, Rio Grande, XV, n. 96, jan. 2012. Disponível em: $<$ http://www.ambitojuridico.com.br/site/?n_link $=$ revista_artigos_leitura\&artigo_id $=11029 \&$ revista_caderno $=19>$. Acesso em jun. 2016.
} 
O início do mandato da presidente já se caracterizava instável com a entrada de recursos pela oposição para a cassação de seu mandato. A disputa política que permaneceu mesmo após as eleições inviabilizou a administração e a atuação do governo no país, aprofundando não só a crise política, com a paralisação de um congresso fragmentado; mas também econômica, na qual a inflação e falta de credibilidade para investimentos se fizeram presentes.

A falta de governabilidade da presidência também pode ser entendida a partir do desgaste da imagem do Partido dos Trabalhadores (PT) e a corrosão da base de apoio governista, que se deu, principalmente, com o início da Operação Lava-Jato. Esta, que é a maior investigação federal de corrupção e lavagem de dinheiro já realizada pelo ministério público (MPF, [s.d]), fomentou grandes protestos, que deram aura de legitimidade ao processo de impeachment, apoiado nas chamadas pedaladas fiscais, classificadas como um crime de responsabilidade fiscal.

O processo de impeachment, desse modo, é o resultado do desgaste político da presidente Dilma Rousseff somado ao escândalo de corrupção, polarização do Congresso Nacional e crise econômica. Nesse sentido, o impeachment será compreendido, aqui, como a principal tradução da crise política pelo qual o país passa. Os efeitos do processo, no entanto, não recaem apenas sobre o Brasil, mas, sobretudo, em seus parceiros do Mercosul.

\section{Atores e interesses}

A crise política brasileira desperta preocupação por parte dos países vizinhos, uma vez que o Brasil é compreendido como líder situacional e instrumental da região, ou seja, ele influencia medidas de outros países, bem como é capaz de intervir em momentos críticos na região (Miranda, 2014). De fato, o país é a maior economia da América do Sul, no entanto, o cenário que antes era de prosperidade vem se modificando. De acordo com os dados apresentados pelo IBGE (2016), o PIB brasileiro teve uma queda de 3,8\% em relação ao ano de 2014 e seu déficit público, que representa 73,7\% do PIB, passou a ser o maior do continente sul americano. O atual quadro econômico do país

\footnotetext{
${ }^{6}$ FALTA de representatividade política da população é abordada em evento da OAB. Disponível em: $<$ http://consultor-juridico.jusbrasil.com.br/noticias/232809961/falta-de-representatividade-politica-dapopulacao-e-abordada-em-evento-da-oab>. Acesso em: 6 out. 2016.
} 
não só lhe é difícil, como também coloca em risco as relações comerciais que são fundamentais para a região.

Outro fator que deve ser analisado é o próprio momento institucional pelo qual o Brasil passa. O processo de impeachment brasileiro, além da sua relação clara com a economia, levanta questões sobre a força da democracia brasileira, que ora é classificada como sólida, ora como frágil por seus vizinhos membros do Mercosul. As avaliações acerca da legitimidade do impeachment pelos jornais destes países revelam o posicionamento e os interesses por de trás de cada um, fazendo com que a análise do período proposto seja essencial para uma ampla compreensão à nível nacional e internacional do momento brasileiro.

\section{a) Argentina}

As relações do Brasil com a Argentina são de grande importância, na medida em que estas possibilitaram a influência regional brasileira tanto na área política, quanto na econômica, além de fornecerem as bases para projetos de integração regional, segurança e cooperação política entre os Estados da América do Sul, desenvolvidos pelo Brasil (Lessa, 2010, p. 122). A proximidade com a Argentina, como defendido pelo Itamaraty, traduz-se em um esforço para a construção de um espaço de paz e cooperação na região (MRE, [s.d.]). A manutenção de boas relações entre os países é essencial para não só o desenvolvimento e crescimento da região, mas também para a garantia da paz.

No que tange as relações comerciais, a Argentina representa uma importante parceira na região para o Brasil. Entre 2003 e 2015, o comércio bilateral entre ambos os países teve um crescimento de $150 \%$, evidenciando uma intensa relação entre os países. Ainda em 2015, a Argentina era o terceiro destino das exportações brasileiras (MRE, [s.d.]).

A avaliação da crise brasileira por parte do país vizinho não pode ser entendida sem levar em consideração o fato de este ter passado por uma crise econômica profunda similar à brasileira, com inflação alta e dados maquiados, no início dos anos 2000 e que repercute até os dias atuais. Em um contexto no qual o líder da região passa por uma forte crise, os jornais apontam que a recuperação econômica da Argentina pode ser co- 
locada em xeque em conjunto com o aprofundamento da crise brasileira, na medida em que a crise impossibilitaria trocas comerciais favoráveis a ambos os países (ZÁRATE, 2016).

É interessante notar como a ideia de "jovem democracia", um ponto de convergência entre os dois países, está presente na avaliação da crise (GOSMAN, 2016), que vem sendo retratada como uma guerra política. Dentro dessa perspectiva de dualidades, portanto, supõe-se a existência de vencedores e vencidos, sendo essencial estabelecer quem são os lados dessa batalha. A comparação com o golpe de 1964 e o destaque dado à incoerência do pedido do impeachment, que possui apoiadores investigados, dentre eles o presidente da Câmara, Eduardo Cunha, por corrupção, é um indicador dessa percepção em artigos de opinião que o jornal traz.

É possível notar a ênfase dada pelo jornal Clarín à fragilidade das acusações a presidente Dilma Rousseff, na primeira quinzena de abril, antes do processo de impeachment passar pela Câmara dos Deputados. Em uma de suas notícias em que apresenta os pontos chaves da "batalha política", o Clarín colocou como três desses pontos a fragilidade da acusação que serve de base para o impeachment, as chamadas pedaladas fiscais, e o paradoxo que é acusação vir de políticos investigados por corrupção no caso da Petrobras (CLAVES..., 2016).

O jornal La Nación, por outro lado, apresentou uma posição de cautela mais firme em relação a legitimidade do processo de impeachment. Através de um artigo escrito por Aníbal Pérez-Linãn, no jornal, é possível constatar essa posição. Em seu texto, o autor apontou para a existência de dois principais erros no julgamento político da presidente Dilma: o primeiro reside na ideia de que o Partido dos Trabalhadores deve deixar a presidência por ter perdido o apoio maioritário; e o segundo seria o de denunciar o julgamento político como uma tentativa de golpe (PÉREZ-LINÃN, 2016).

O jornalista Marcelo Cantelmi, que escreveu para o panorama internacional do Clarín, apontou para o fato que se não houve um delito concreto por parte da presidente como o caso de do ex-presidente brasileiro Fernando Collor e o ex-presidente paraguaio Fernando Lugo, o processo de contra Rousseff simboliza as debilidades institucionais e legais (CANTELMI, 2016). A fragilidade da democracia brasileira é, nesse sentido, uma das percepções acerca do impeachment apresentadas no jornal.

A polarização política também é um importante enfoque dos jornais argentinos. Tanto o Clarín, quanto o La Nación noticiaram a instalação de muros para separar as manifestações pró e anti-impeachment como um mecanismo que visava evitar conflitos 
violentos entre os dois lados. O La Nación, em sua manchete, ainda chamou atenção para o "nervosismo em Brasília". Segundo o jornal, "as autoridades brasileiras não querem que a verde e vasta Explanada dos Ministérios se converta em um sangrento campo de batalha" (MUROS..., 2016). A própria utilização do termo "batalha" em excessivas manchetes, bem como a noção de "nervosismo" sugere uma percepção de conflito por parte da imprensa.

É possível notar ainda certa preocupação com os resultados da crise política brasileira para com seus vizinhos, sobretudo a Argentina, que sofre diretamente com o comércio e economia. Um elemento revelador dessa preocupação, além das matérias dedicadas ao assunto, é a própria percepção dos jornais acerca do impeachment. $\mathrm{O}$ modo como este foi depreendido pelos jornais argentinos, sem muitos posicionamentos claros, no qual ora se percebe um tom ora pró-impeachment e ora anti-impeachment. Além disso, percebe-se também um silêncio editorial, que pode ser associado à certa dependência econômica da Argentina, que destina grande parte de suas exportações ao Brasil. Isso se dá porque conservar a imagem do Brasil democrático, sem criar e influenciar precipitadamente a opinião pública acerca da legitimidade do processo, passa a ser fundamental para uma relação estável com seu principal parceiro comercial.

De certo modo, nota-se uma indefinição quanto à legitimidade do processo de impeachment na primeira quinzena do mês de abril. No entanto, percebe-se uma mudança significativa na posição dos jornais com o desenrolar do processo de impeachment, sobretudo quando este foi aprovado na Câmara dos Deputados, no dia 17 de abril.

Com o impeachment em fase de concretização, a percepção dos jornais tornouse mais claras. Pode-se notar no Clarín, por exemplo, um tom mais pró-impeachment. Em um artigo de opinião com a manchete "Brasil: es preciso repensar el juicio político" (PÉREZ-LINÃN, 2016), colocou-se justamente a necessidade de se repensar a legitimidade da destituição Se antes o jornal, como analisado, percebia o impeachment como um processo sem bases sólidas, agora já não faz referências a uma possibilidade real de golpe; mas de uma destituição da presidência que não é capaz de governar.

Em uma matéria para o jornal La Nación, Arturo Pfeiffer propõe que o julgamento a Dilma é mais de ordem política, na medida em que a presidente se apresenta inábil para governar (PFEIFFER, 2016). Além disso, nota-se ainda que a percepção acerca das pedaladas fiscais, que antes eram entendidas como acusações frágeis, também mudou. Agora, elas passaram a ser apreendidas como uma acusação legítima e de base constitucional. 
É possível identificar no jornal La Nación, todavia, uma posição de cautela acerca da legitimidade do impeachment. Embora se perceba uma percepção do impeachment como ilegítimo a partir do artigo de opinião "Brasil abre uma perigosa caixa de pandora" (LODOLA, 2016), que visa analisar o processo de destituição da presidente, a percepção do jornal não pode ser facilmente resumida a esta. Se por um lado a autora do artigo em questão afirma que o que se passou no Brasil não foi um golpe como conhecido, com apoio de militares, mas uma "remoção antidemocrática do Executivo, forçando a utilização de procedimentos legais" (LODOLA, 2016); por outro, um editorial publicado pelo jornal deixa transparecer o cuidado deste em não se posicionar pró ou anti impeachment.

No editorial intitulado "A encruzilhada brasileira", o jornal destaca o "cenário sombrio" pelo qual o país passa, a suspeita de corrupção do vice-presidente Michel Temer e afirma que "indubitavelmente, a decisão de colocar em curso o processo de destituição é uma mancha para a democracia” (LA NACIÓNa, 2016). Assim, o que é percebido é certa fragilidade da democracia brasileira, que não necessariamente se dá pela possibilidade de um golpe, mas pela falta de representatividade da população.

O jornal La Nación, dentro dessa perspectiva, enfatiza a falta de legitimidade da presidente para como consequência de seus próprios erros. Em uma nota publicada pelo jornal que se destinava a explicar o impeachment de Dilma Rousseff, o La Nación traduz o histórico da tensão política como "O caminho para o inferno de Dilma” (EL CAMINO..., 2016). A honestidade de Dilma também é questionada pelo jornal, que vê as manifestações civis como um impulsionador do processo de destituição. A percepção de que é a sociedade civil, descontente com a falta de gerência do governo e não representada, a grande propulsora do processo que permite identificar o tom de legitimidade dado para o impeachment.

O que se pode observar no mês de abril, portanto, é como o posicionamento dos jornais argentinos se modificaram de acordo com a acentuação da crise política, traduzida no processo de impeachment. Embora em um momento inicial os jornais percebessem a crise como resultado de uma ingovernabilidade, mas que não era passiva legalmente de destituição ou de modo mais imparcial; com o avanço do impeachment, eles se apresentaram uma percepção do impeachment como legítimo. Esses posicionamentos se dão, sobretudo, devido a um imperativo de manter as relações econômicas e políticas entre o Brasil e Argentina estáveis, uma vez que na segunda quinzena do mês de abril o processo do impeachment já indicava o seu sucesso. 
Em maio o jornal La Nación publicou um editorial, onde afirma que "é de se esperar que o maior sócio comercial argentino se adere a lei, bem como aos cuidados com a paz social, mantendo em ordem seus esquemas institucionais" (LA NACIONb, 2016). Além disso, o editorial destaca que apenas os países chamados bolivarianos saíram em defesa da ideia de golpe no Brasil.

Outra importante colocação feita pelo jornal no editorial é a de que "depois de treze anos de esquerda, um novo tempo se abre para o Brasil”" (LA NACIONb, 2016). É interessante notar como o editorial é publicado cinco dias após a declaração do presidente argentino Mauricio Macri declarar respeito pelo novo governo, em que afirmava que "o Governo Argentino continuará dialogando com as autoridades constituídas a fim de seguir avançando com o processo de integração bilateral e regional” (CUÉ, 2016). Se antes Macri apresentava uma posição de cautela assim como jornal La Nación, agora ambos apresentam uma posição de alinhamento acerca da legitimidade do impeachment.

Em outro editorial, cujo título é "Charlatanismo Político", o jornal La Nación propõe que não há um golpe no Brasil e faz uma crítica aos governos vizinhos. De acordo com La Nación,

não houve no país irmão 'um golpe brando' como sustentam Chomsky e outros intelectuais que tem deixado passar por alto a Fidel Castro alguns de seus piores crimes políticos, nem tem observado com preocupação situações graves e penosas como as da Venezuela e Nicarágua (LA NACIÓN, 2016)

Em um cenário de destituição, que veio a se concretizar no fim de agosto, a Argentina não poderia colocar em risco sua relação com o país. Portanto, afirmação da legitimidade do processo pode ser percebida como uma estratégia essencial para que ainda se conserve a imagem do Brasil democrático na opinião pública argentina. Dentro dessa perspectiva, a relação entre a percepção do jornal com a política externa do país se dá justamente pelo imperativo de manter a parceria entre os países estável e, sobretudo legítima aos olhos da sociedade argentina.

É justamente diante da necessidade de formar uma opinião pública que vá de encontro com os interesses dos atores tomadores de decisão dentro da política externa que se torna essencial posicionamentos mais claros e firmes, como se nota com o desenrolar do processo de destituição. Outra questão que deve ser levada em consideração é o modo com que os jornais discutem a política brasileira para fazer uma reflexão sobre seu próprio governo e seus interesses. Assim, a mudança da avaliação da crise brasileira 
por parte dos jornais argentinos se dá de forma estratégica e alinhada a política externa, de modo a garantir a estabilidade das relações entre os países.

\section{b) Paraguai}

O Paraguai é uma das menores economias da América Latina. No entanto, na última década, segundo o Banco Mundial, a economia paraguaia apresentou o maior índice de crescimento, a uma média de 5\%, quando comparado aos vizinhos (BANCO MUNDIAL, [s.d.]). No entanto, $30 \%$ de sua população ainda vive em condição de pobreza (PAÍS..., 2013), o que permite identificar a grande desigualdade social no país.

As relações entre o Paraguai e o Brasil são de extrema importância, sobretudo, para o crescimento de ambos os países. Se por um lado o Brasil é dependente da energia proveniente da hidrelétrica binacional de Itaipu, por outro o Paraguai precisa de rotas para escoamento de sua produção, uma vez que não possui acesso direto ao mar. É diante desta ausência que o Brasil se torna um importante parceiro. A aproximação dos países se deu com a construção da Ponte da Amizade, em 1965, que permitiu o acesso paraguaio via rodovia ao oceano Atlântico para a escoamento de sua produção, incentivando, desse modo, suas exportações e o desenvolvimento de uma indústria competitiva (MRE,

No que diz respeito ao comércio bilateral entre Brasil e Paraguai, este apresentou um crescimento significativo entre o ano de 2002 e 2013 de cerca de $300 \%$, evidenciando um estreitamento das relações comerciais entre os países (MRE, [s.d.]). Dentro desse contexto, é essencial compreender o papel fundamental de parceiro que o Brasil exerce na economia paraguaia.

No que tange a legitimidade do processo de impeachment que foi instaurado no Brasil, cabe ressaltar a similaridade do processo com a destituição do presidente paraguaio Fernando Lugo, que se iniciou com o pedido do Partido Colorado ${ }^{7}$, em 2012. O impeachment do presidente, considerado pelas nações latino-americanas e pela Comissão Interamericana de Direitos Humanos como ilegítimo, resultou no isolamento político do país na região e sua suspensão no Mercosul, a partir do protocolo de Ushuaia II $^{8}$.

\footnotetext{
${ }^{7}$ O Partido Colorado, também conhecido como Partido Nacional Republicano, é caracterizado por ser um partido de centro-direita e nacionalista. Para saber mais: http://www.anr.org.py/

${ }^{8} \mathrm{O}$ protocolo de Ushuaia II faz referência ao compromisso com a democracia no Mercosul. De acordo com o artigo 1: o presente Protocolo será aplicado em caso de ruptura ou ameaça de ruptura da ordem democrática, de uma violação da ordem constitucional ou de qualquer situação que ponha em risco o legitime exercício do poder e a vigência dos valores e princípios democráticos. Para saber mais, acessar: http://dai-mre.serpro.gov.br/atos-internacionais/multilaterais/protocolo-de-montevideu-sobre-
} 
A destituição de Lugo e a possível destituição de Dilma Rousseff abrem margem para traçar um paralelo entre ambos os casos e as possíveis consequências. O julgamento, por parte de organizações multilaterais, como a OEA e o Mercosul, do impeachment sofrido pelo primeiro acarretou na suspensão do Paraguai no bloco regional do Mercosul. Isso se deu através da interpretação destas acerca do que é a democracia e seus mecanismos legítimos.

O impeachment da presidente Rousseff também pode ter consequências parecidas, caso seja considerado institucional pelas organizações. Apesar do peso político que o Brasil tem para o Mercosul, o que funciona como um fator de mitigação das possíveis consequências do impeachment, a avaliação do processo de impeachment no Brasil como ilegítimo por parte da OEA e a já experenciada suspensão paraguaia do Mercosul trata-se um obstáculo político a ser enfrentado em caso de êxito da destituição.

Embora a avaliação por parte dos foros multilaterais regionais seja de oposição ao impeachment da presidência brasileira, a avaliação da imprensa paraguaia acerca da crise política brasileira e a possibilidade de destituição é divergente. Através do conjunto de notícias publicadas e relacionadas à atual situação do Brasil, é possível notar um alinhamento da percepção paraguaia a oposição política brasileira

A representação de Dilma, em uma matéria publicada pelo $\mathrm{ABC}$ Color, como "rainha de ferro", "inflexível" e "sem carisma" (DILMA..., 2016) é um dos destaques do jornal ABC Color, o de maior circulação nacional. A caracterização de Dilma nos jornais é um dos principais fatores para identificar o posicionamento paraguaio: a favor da destituição. Os jornais desconsideram a possibilidade de um golpe no país, fazendo poucas referências a essa ideia e, quando necessário, utilizando aspas com o objetivo de esvaziar sua verdade como é o caso da matéria publicada no jornal Hoy com a manchete “Advertem 'resistência' se avança 'golpe' a Rousseff”' (ADVIERTEN..., 2016). No corpo da notícia, chama-se atenção para incitação ao crime por parte dos movimentos sociais, o que, dentro de uma disputa política, sugere, a falta de legitimidade por parte dos manifestantes.

A partir da matéria do jornal "Dilma, a ex-guerrilheira que luta pela sua presidência" (DILMA..., 2016b), a ABC Color deixa transparecer sua posição. Ao caracterizar Dilma como "arrogante", "tecnocrata sem carisma, firme e severa" e afirmar que a sua eleição foi um "acidente presidencial”, o jornal atribui aspectos negativos a figura

compromisso-com-a-democracia-no-mercosul-ushuaia-ii-firmado-por-ocasiao-da-xlii-reuniao-do-cmc-ecupula-de-presidentes-do-mercosul-e-estados-associados/ 
da presidente, apresentando-a como o potencial problema do país. A grande ênfase do jornal se dá no processo de impeachment, principalmente, em suas fases. Não há muitas matérias dedicadas a questionamentos acerca da legitimidade do processo, o que sugere, justamente, a percepção de legalidade do processo por parte do ABC Color.

Outra uma crítica ao populismo que governou a região, principalmente na Argentina e Brasil. Em uma matéria do jornal, Rolando Niella apontou que as causas centrais do colapso destes governos foram a sistemática aplicação de políticas equivocadas e a necessidade de corrigi-las, por motivos ideológicos (NIELLA, 2016). Além disso, ele afirma que os governos populistas têm se autorizado a não respeitar as leis e normas morais básicas para a convivência na democracia.

A crise política no Brasil tem sido percebida pelos jornais ABC Color e Hoy Paraguay como uma verdadeira "batalha". O termo foi constantemente utilizado para descrever a disputa política no Brasil. Manchetes como "Batalha até o último minuto pela Presidência" (BATALLAa..., 2016), do jornal Hoy e "Batalha feroz para decidir o destino de Rousseff' (BATALLAb..., 2016, do jornal ABC Color são exemplos.

Dentro da lógica de batalha, o jornal Hoy destacou a determinação de Dilma em seguir lutando pelo seu mandato frente à ameaça de destituição. Interessante notar como a qualificação "de esquerda" à presidente tem sido bastante explorada nas matérias. O que se constata através da qualificação é a percepção por parte do jornal de uma polarização política, cujos lados devem ser identificados. As posições "esquerda" e "direita", explicitados pelos jornais, caracterizam, nesse sentido, as ideologias políticas em disputa. Assim, a batalha seria, justamente, política e ideológica.

Ainda no que tange a ideia de batalha, o jornal ABC Color comparou o processo de busca por votos na Câmara dos Deputados com uma "guerra de trincheiras parlamentares" (BATALLAb..., 2016). A guerra, como colocado pelo jornal, seria para a destituição da "presidente de esquerda, Dilma Rousseff”. Novamente, a qualificação "de esquerda" é mobilizada para pontuar o posicionamento da presidente. A caracterização dos lados da "guerra"/ "batalha", portanto, configuram uma tendência em ambos os jornais.

A segunda quinzena de abril, através das matérias dos jornais, é marcada pela ênfase no processo de impeachment e suas consequências para a região. O jornal $\mathrm{ABC}$ Color passou a dedicar suas notícias às reações daqueles que consideram o julgamento político da presidente sem base legal, como Maduro, Mujica, Lula, o ministro Nelson Barbosa e a própria Dilma Rousseff. O debate sobre o golpe é colocado, mesmo que 
marginalmente, quando o jornal passa a utilizar a palavra em suas manchetes, mesmo que entre aspas, sugerindo que se trata de uma narrativa. Assim, se na primeira semana utilizava-se com frequência o termo "julgamento político", a segunda é marcada por matérias que traziam as denúncias de "golpe".

O jornal também apontou que o "gigante sul americano" estaria à deriva, o que sugere uma falta de controle e governabilidade de um país com grande peso e influência na região (EL GIGANTE, 2016). Além disso, destacou a difícil situação regional, em que o principal sócio comercial do Paraguai, o Brasil, apresentou uma queda de 3,7\% do PIB devido à crise política e econômica que arrasta o país. O que se constata é uma preocupação com as consequências da crise para a região que depende da estabilidade brasileira para crescer.

O jornal Hoy Paraguay, por outro lado, manteve a ênfase nos processos legais do impeachment, destacando a falta de apoio do senado à presidente e a aprovação deste na Câmara dos Deputados, no dia 17 de abril. Houveram poucas matérias que cogitava a possibilidade de golpe. Estas apenas apresentavam as reações da defesa da própria presidente e do Movimento dos Trabalhadores Sem Teto, ligado ao Partido Trabalhadores, como no caso da notícia "Advertem resistência, se avança o golpe" (ADVIERTEN..., 2016). A partir destas, infere-se que a percepção do jornal acerca das acusações de golpe é a de que a narrativa está mais relacionada com uma questão de ideologia, do que, de fato, em uma inconstitucionalidade.

Ao analisar a conjuntura brasileira a partir dos jornais paraguaios, observa-se que a percepção por parte destes está também relacionada com o seu próprio processo de impeachment. Se internamente ele foi considerado legítimo, internacionalmente a destituição do ex-presidente Lugo se mostrou passível de contestações. Uma importante colocação a ser feita, para uma análise mais complexa da percepção paraguaia, diz respeito a presidência. Hoje ela é ocupada pelo Partido Colorado, partido liberal radical que abriu o pedido da destituição e que possui maior força política no país ${ }^{9}$, conjuntura semelhante a experenciada pelo Brasil. Nesse sentido, assumir a legitimidade do processo brasileiro é confirmar a narrativa de legitimidade do caso paraguaio, tão questionado internacionalmente.

Além disso, é possível notar uma crescente preocupação com o regionalismo por

\footnotetext{
${ }^{9}$ A força política do Partido Colorado pode ser constatada pela sua permanência no poder por mais de 61 anos. O Paraguai, segundo a BBC, é o país com menos alternância de poder da América Latina. http://www.bbc.com/portuguese/noticias/2013/08/130815_paraguai_alternancia
} 
parte do jornal ABC Color. Após o afastamento de Dilma da presidência e mesmo depois de sua saída, a principal pauta dos editoriais foi o Mercosul. No editorial "Novos tempos no Mercosul", ABC Color afirma que tanto a Argentina quanto o Brasil estão realizando importantes mudanças políticas que permitem levantar esperanças de que o Mercosul renasça das cinzas (ABC COLOR, 2016). O abandono ao populismo e a o rompimento com a esquerda é um dos principais fatores, que segundo o jornal, permite que o bloco regional seja conduzido de modo que "recupere sua autêntica missão de promover a integração econômica" (ABC COLOR, 2016).

O que fica claro com o editorial que é publicado quase um mês depois da aprovação do impeachment no Congresso brasileiro é que a legitimidade do impeachment não é colocada em dubiedade em momento algum pelo jornal. A percepção dos jornais, pelo contrário, é a de que a destituição da ex-presidente brasileira Dilma Rousseff é uma consequência de uma série de fatores como baixa popularidade e uma crise econômica, cuja origem encontra-se na má gestão do governo, responsável por maquiar as contas públicas.

Desse modo, o que se constata através da análise feita é que a percepção do impeachment brasileiro por parte dos jornais paraguaios não pode ser entendida se não levar em consideração fatores domésticos como o próprio processo de destituição do presidente paraguaio Fernando Lugo, em 2012, e seus interesses nas relações com o Brasil. O destaque aos passos legais do processo de destituição, pelo jornal Hoy, mas também uma ênfase na legitimidade do impeachment por parte do ABC Color revelam essa

posição.

O que é interessante notar é justamente a forma com que a percepção dos jornais está relacionada com a política doméstica do Estado paraguaio. Dentro dessa perspectiva, Putnam contribui para a análise na medida em que propõe uma ênfase na luta política para se compreender os determinantes domésticos da política externa e das relações internacionais (PUTNAM, 2010, p. 150). De fato, a percepção de legitimidade do impeachment brasileiro está fundamentada para além da própria história escrita por Fernando Lugo. Trata-se de atender os interesses domésticos do país, que depende fundamentalmente da economia brasileira e, portanto, deve garantir a narrativa de legitimidade do processo. Assim, no que diz respeito a política externa e as relações internacionais entre o Paraguai e o Brasil, observa-se um alinhamento dos jornais, que também constituem um grupo de pressão, com a política do país. Para Putnam, a luta política envolvida em negociações internacionais pode ser 
entendida a partir do jogo de dois níveis: o nível nacional e o internacional. No primeiro, os grupos domésticos pressionam o governo a tomar políticas que favoreçam a seus interesses, já no segundo, os governos nacionais buscam maximizar suas habilidades de modo a atender as pressões domésticas. Nesse sentido, nenhum dos dois jogos poderiam ser ignorados pelos decision makers, na medida em que os países são interdependentes e soberanos (PUTNAM, 2010).

A partir desta ótica, pode-se concluir que a percepção dos jornais paraguaio é filtrada por questões de interesse doméstico, que influencia e é influenciado diretamente pela política externa do país. Assim, ao compreender que a mídia, aqui representada pelos jornais, é importante componente da política doméstica e, portanto, faz parte da luta política, proposta por Putnam, pode-se afirmar que ela tem um importante papel dentro da política externa do país.

\section{c) Uruguai}

O Uruguai é um dos principais parceiros estratégicos do Brasil na América Latina, sendo a Unasul e o Mercosul as principais instituições de cooperação entre ambos os países (MRE, [s.d.]). Atualmente, o Uruguai é caracterizado pela sua política governamental voltada para questões sociais, que ficou conhecida internacionalmente pelo desempenho do ex-presidente José Mujica. O país é um dos mais desenvolvidos da América do Sul com o PIB equivalente a 56,8 bilhões de dólares e ocupa a primeira posição em qualidade de vida e desenvolvimento humano da região.

A percepção pela imprensa uruguaia acerca do impeachment é pautada pela noção de falta de representatividade do governo. No jornal de centro direita do país, El Observador, a crise é apresentada como uma "deriva institucional", que possui origem na corrupção estrutural, que o Partido dos Trabalhadores levou ao limite máximo. De acordo com o jornalista Ricardo Galarza, ao descobrir o grande esquema de corrupção, a população "não está mais disposta a tolerá-la e pede nas ruas a queda do governo, de Dilma, Lula e todos que devem cair" (GALARZA, 2016).

Ainda na análise feita por Galarza, crise é percebida como consequência de um governo corrupto e que se tornou ilegítimo devido a sua irresponsabilidade com as contas públicas e pela significativa falta de apoio da população, que não se sente representada. Outro ponto destacado é a atuação independente, o que sugere, na realidade, a separação dos poderes executivo, legislativo e judiciário. De acordo com o jornalista, "no 
meio ao grande infortúnio, a Justiça tem atuado com independência e firmeza", ao passo que o governo petista defende a acusação de golpe (GALARZA, 2016).

O jornal também aponta para a polarização política dentro do país e de como ela é responsável pela criação da ideia de golpe de Estado dentro de um regime democrático. As próprias manifestações são percebidas como convocações dos partidos da situação e dos opositores (EL CALVARIO...,2016). A matéria "O Calvário do Impeachment" publicada pelo El Observador, em certa medida, revela a percepção do jornal acerca da legitimidade do processo.

Com o objetivo de responder perguntas as "Como funciona este mecanismo? Usá-lo implica um 'golpe' de estado como afirmam alguns? Além do Brasil, onde mais se prevê na Constituição?” (EL CALVARIO..., 2016), o jornal afirma que o impeachment se trata de um mecanismo de controle parlamentar, previsto tanto na Constituição brasileira quanto em outros países, como é o caso do próprio Uruguai. Acerca da possibilidade de um golpe, a matéria propõe que este se trata, na realidade, de um discurso do Partido dos Trabalhadores. A percepção de legitimidade do processo pode também ser observada com a seguinte passagem que recorre a um discurso de autoridade, onde se faz uma importante colocação sobre as perspectivas políticas e o jurídicas do impeachment :

\footnotetext{
Segundo explicou o cientista político Oscar A. Bottinelli, o julgamento político tem essa denominação porque os organismos que os realizam são políticos, mas seu conteúdo é jurídico. "O julgamento político leva em consideração os delitos graves ou violação da Constituição e leis e não se deve ou confundir com a censura parlamentar", explicou Bottinelli (EL CALVARIO...,2016)
}

A percepção da legalidade e legitimidade do impeachment do jornal El Observador pode ser observada pelas matérias publicadas na primeira quinzena do mês de abril. A primeira constatação é a de que a maior parte das notícias dedicadas a crise política do Brasil foram a respeito do processo de impeachment. Além disso, não houveram menções a possibilidade de golpe. As manchetes se referiam à "destituição" e "processo de julgamento político", o que indica essa percepção, na medida em que não se noticia e não propõe um debate em torno da ideia.

Outra tendência que pode ser observada da imprensa uruguaia é o pouco noticiamento da ideia de golpe de Estado. O jornal El País, assim como o El Observador, também não fez referência a um possível golpe de Estado no Brasil. Ao contrário, é apresentado que não haverá golpe no Brasil, mas sim a efetivação e ativação das leis 
previstas na Constituição. Ignácio Sienra, em um artigo de opinião no jornal El País, cujo título é "Não haverá golpe no Brasil" (SIENRA, 2016) corrobora essa interpretação.

O artigo dá ênfase às manifestações pacíficas realizada por milhões de cidadãos contra o governo de Dilma e os motivos pelos quais o impeachment é legal. Além disso, é interessante notar como o julgamento é interpretado. De acordo com Sienra, a causa deste é a adulteração das contas fiscais realizado pela presidente. Nesse sentido, a destituição não poderia ser associada a um golpe, afinal, o processo é previsto pela Constituição.

Dentro dessa perspectiva, Sienra faz uma crítica ao governo Uruguai, afirmando que se de um lado o julgamento procede no Brasil, do outro, em seu país, sai um "imbecil" dos organismos com o Plenário e protege o parceiro em apuros (SIENRA, 2016), o que sugere a eficiência da justiça brasileira e, portanto, a legitimidade do processo. No que tange à política externa, o jornalista ainda faz uma provocação ao atual governo quando lança questões como "O que o governo uruguaio vai fazer com o Brasil? Ai meu Deus! Ira-o expulsar do Mercosul como o Paraguai? Irá aplicá-lo a máxima del chambón de que o político está por cima do jurídico?” (SIENRA, 2016).

A segunda quinzena do mês de abril é marcada pela continuidade das posições dos jornais. O jornal El Observador noticiou pouco sobre as interpretações de golpe. No entanto, dedicou uma matéria para a publicação sobre a posição do Partido Frente Ampla, que qualificou o julgamento político como um "processo de golpe de Estado" (EL FRENTE..., 2016). Nota-se, aqui, um desalinhamento das percepções do governo do Uruguai com os jornais. De acordo com a notícia, o "documento de esquerda" da presidência uruguaia considerava que o objetivo de tirar Dilma e o PT da presidência, por parte da direita e setores associados, entre os quais estão a Rede Globo, a Federação de Indústrias de São Paulo e setores do Poder Judicial, é retomar o poder político econômico para tirar a liderança do Brasil no processo de integração regional soberana e autônoma através do Mercosul, Unasul e Celac (EL FRENTE..., 2016). A

O jornal El País também manteve seu posicionamento. As causas da crise política brasileira são atribuídas ao governo de Dilma Rousseff, o Partido dos Trabalhadores, seus aliados e a administração anterior presidida por Lula, como apontou a jornalista e diretora do jornal, Julia Larreta (2016). Além disso, a matéria publicada na segunda feira, após a votação ocorrida no domingo, 17 de abril, intitulada "Dilma Rousseff a um passo da saída”, apresenta o resultado da votação do impeachment como uma possível 
"saída do lulismo" (DILMA..., 2016a). A partir desta, é possível notar a crítica explícita que o jornal faz ao governo brasileiro.

O afastamento definitivo da presidente Dilma Rousseff, com a conclusão do processo de impeachment, permitiu observar com ainda maior clareza as percepções dos jornais. A exemplo, tem-se a publicação de um editorial pelo El País Uruguay, no qual torna-se evidente a posição de defesa da legitimidade do processo. De acordo com o jornal, o processo, que começou em novembro de 2015, cumpriu todas as etapas exigidas pela lei (EL PAÍS, 2016). Além disso, afirmou que "brasileiros, uruguaios e toda região, apostamos pela pronta recuperação do grande vizinho" (EL PAÍS, 2016).

Como é possível observar, o posicionamento político da imprensa não se dá em consonância com a posição governamental do Uruguai, que entende o impeachment como um processo ilegítimo. Em um Comunicado do Ministério de Relações Exteriores do Uruguay, o governo afirmou que tem acompanhado com atenção o processo de destituição da "presidente eleita legitimamente pelo povo brasileiro" e o qualificou como uma "profunda injustiça" ( URUGUAY, 2016).

A percepção dos jornais uruguaios revela um descontentamento com o próprio governo, enquanto enxerga um importante processo de mudança política no Brasil. Assim, os jornais analisados desempenham, no nível doméstico, a função de construção de uma opinião pública que motive mudanças nas ações governamentais, que vão de encontro aos interesses do grupo. Dessa forma, os jornais estão presentes na luta política sugerida por Putnam, que também informa e influencia a política externa.

\section{d) Venezuela}

A Venezuela possui um papel fundamental na integração política, social e cultural da América Latina. Com uma esquerda fortalecida, a ideologia chavista da Venezuela é uma das suas principais características. O país passou pela chamada Revolução Bolivariana na década de 1990, sob o governo do presidente Hugo Chávez. O bolivarianismo, ideologia que orienta a política venezuelana, ficou conhecido como conjunto de políticas que questionam o neoliberalismo e o Consenso de Washington (GOMBATA, 2014). Acerca da relação entre Brasil e Venezuela, torna-se importante destacar a aproximação dos países durante o governo do PT, notadamente por um esforço de Lula na medida em que articulava o trabalhismo como instrumento de diálogo com Chávez.

No contexto da crise política e econômica brasileira, a imprensa venezuelana vem apontando, com grande ênfase, para a possibilidade da realização de um golpe de 
estado por parte da elite conservadora do país. É possível observar essa tendência as partir das matérias publicadas no Correo del Orinoco. A primeira quinzena do mês de abril dedicou matérias com apoio a presidente Dilma Rousseff, dentre as quais está a convocação do povo venezuelano para um grande tuítaço com a hashtag "ElMundoconDilma" (GOMÉZ, 2016). Nesta, fala-se que a presidente é objeto de uma campanha de descrédito realizada pela direita nacional e internacional.

A percepção da crise brasileira como resultado de um esforço das camadas conservadoras e liberais é também uma tendência apresentada pelos jornais. Observa-se que, tanto no jornal Correo del Orinoco, quanto no El Nacional, as notícias estão relacionadas a uma única visão: a do governo da presidente Dilma Rousseff. Assim, é possível notar como as notícias apresentam posturas favoráveis ao governo petista, buscando defendê-lo. Outro mecanismo do jornal venezuelano para deslegitimar o processo de impeachment é a vinculação estratégica deste ao neoliberalismo, na medida em que se sustenta este estaria servindo a interesses de pequenos grupos.

Em um artigo de opinião no jornal Correo del Orinoco, Sérgio Rodriguez, compara o processo de impeachment com o golpe de 1964. No entanto, a percepção é a que de hoje bastam os meios de comunicação para que ocorra o golpe. De acordo com ele, estes constituem, atualmente, "um componente da oligarquia que, usando outros tipos de armas, tão letais como aquelas [militares], são os encarregados de criar as condições para o extermínio, o desaparecimento, a morte, a tortura e as demissões dos trabalhadores" (RODRÍGUEZ, 2016). O que se observa é a ligação entre o processo de destituição o com o papel da mídia, identificada como uma força conservadora

O processo de impeachment é percebido também como uma ameaça à sociedade brasileira e como uma tentativa de golpe pelas forças neoliberais. Nesse ínterim, é possível observar o esforço da imprensa venezuelana em denotar um atentado à democracia, ao passo em que busca reconstituir a figura do governo brasileiro como sendo de esquerda, e que prioriza o bem-estar social, em detrimento de privilegiar uma elite restrita. Os jornais levantam pontos como o apoio dos estudantes à presidente Dilma, os brasileiros na rua contra o golpe, ao mesmo tempo em que destacam a perseguição política à Dilma como fascista. Em um artigo de opinião, no Correo del Orinoco, Emir Sader afirma que o novo governo nasceria sob um signo de traição e sobre a base do programa mais conservador e antipopular que existe hoje no Brasil. Além disso, propõe que este seria uma vingança contra os trabalhadores (SADER, 2016).

Outra tendência observada é o destaque da posição de foros multilaterais como a 
OEA e a Unasul, que expressam preocupação com o desenrolar da crise política, como um meio de preterir o impeachment. Os jornais Correo del Orinoco e El Nacional deram ênfase nos pronunciamentos oficiais de Alamagro (OEA) e Ernesto Samper (Unasul), chamando atenção para as possíveis consequências que seriam acarretadas em caso de destituição. Uma colocação que busca igualmente deslegitimar o processo de destituição se dá através da recuperação e reformulação da figura da Dilma. A presidente é retratada como mulher forte, popular, honesta e vítima dos jogos de poder de uma elite $^{10}$.

A segunda quinzena de abril é notadamente marcada por um aumento do emprego do termo "golpe" nas notícias. Há um esforço por parte dos jornais em defender a governo Rousseff através de matérias que possuem como foco a possibilidade de golpe. Noticia-se também as manifestações sociais pró-governo. Nesta, fala-se em "brasileiros nas ruas em rejeição ao golpe" (BRASILEÑOS..., 2016), o que indica um patriotismo, nacionalismo.

Com o desfecho do impeachment, o presidente Nicolás Maduro congelou as relações com o Brasil, afirmando que o processo de impeachment foi um "golpe oligárquico da direita”(MADURO...,2016), além de enviar uma nota ao Itamaraty afirmando que "o Governo brasileiro repudia os termos do comunicado emitido pelo Governo venezuelano (...) sobre a conclusão do processo de impedimento da ex-Presidente da República" (CUÉ, MOLINA, 2016). Interessante notar como, justamente, a percepção dos jornais vai de encontro com a política externa. É ainda válido ressaltar que o jornal Correo del Orinoco é pertencente ao governo venezuelano, o que torna ainda mais evidente os motivos de convergência entre as percepções do jornal e a do governo.

O que se constata é que através destes movimentos, a imprensa da Venezuela estaria buscando conferir legitimidade ao seu próprio governo, na medida em que se apoiaria na defesa do fortalecimento da democracia e da esquerda brasileira. Além disso, buscaria também construir uma imagem da América do Sul, como uma região distanciada dos princípios neoliberais, onde o país tido como líder regional possui características comuns com seu governo.

\footnotetext{
${ }^{10}$ A elite nacional, aqui, é entendida em termos políticos, que busca garantir seus interesses. Cabe ressaltar, que dotada da hegemonia gramsciana, essa elite seria responsável por filtrar informações e criar um consenso acerca da legitimidade do governo.
} 


\section{Destaques da Agenda}

A presente análise de conjuntura buscou revelar as tendências de interpretação da crise brasileira a partir do posicionamento dos jornais dos países membros plenos do Mercosul. Embora as interpretações tenham se apresentado variadas, é possível identificar os principais destaques da agenda, quando tratada a crise política e a legitimidade do processo de impeachment do Brasil. Assim, um dos principais destaques dados pelos jornais é a possibilidade real do impeachment e seus possíveis desdobramentos, sobretudo, econômicos na região.

No que diz respeito a esse ponto, as avaliações dos jornais são díspares. Se por um lado é perceptível um esforço em construir a ideia do perigo de um golpe por parte da imprensa da Venezuela, que permaneceu com esse posicionamento ao longo do mês de abril e após o desfecho do processo, por outro, as imprensas argentina, paraguaia e uruguaia, com diferentes nuances, sustentam a ideia de que o processo de impeachment é constitucional e legítimo.

Outro destaque da agenda é a polarização política que se estabeleceu no Brasil e acentuou a crise no país. A imprensa como um todo noticiou com ênfase a existência de uma disputa política e ideológica, na qual as categorias ideológicas "direita" e "esquerda" estão em conflito e constante disputa. A divisão do país, ao longo da análise, é retratada como um momento importante, em que os interesses não são convergentes e, portanto, torna qualquer possibilidade de consenso ou acordo inviável entre as posições políticas.

Um último ponto ao qual se pode fazer menção é o da crise institucional, na medida em que ele se expressa de forma explícita nos jornais. A corrupção denunciada no âmbito da Operação Lava-Jato é associada pela imprensa à corrosão da base de apoio do governo, fazendo com que o governo não seja mais capaz de governar.

\section{Oportunidades e Desafios}

A crise política e econômica do Brasil tem resultado na deterioração de sua imagem junto aos países vizinhos membros do Mercosul como emergente e de líder regional. A corrupção, a falta de governabilidade, a paralisação do Estado e a ameaça à democracia colocam em risco não só o Brasil, mas também os países vizinhos, principalmente os que compõem o Mercosul. O principal desafio consiste, portanto, na recuperação da imagem e da credibilidade brasileira para a condução do grupo. 
Pode-se considerar a manutenção da liderança brasileira no Mercosul um outro desafio, na medida em que há uma inclinação por parte dos países membros a priorizar relações econômicas e comerciais intra bloco. Ademais, frente a possibilidade de afastamento do principal parceiro a partir da aplicação do Protocolo de Ushuaia II, o que se constata, dentro desse contexto, são esforços por parte dos estados-membros para reconhecer o processo como legítimo e, assim, permitir a estabilidade e a continuidade das relações dentro do bloco regional.

A principal oportunidade identificada pelos dos jornais reside na maior transparência e punição contra a corrupção sistêmica, característica comum aos governos vizinhos. A Operação Lava-Jato e a intolerância da população brasileira para com a corrupção são vistos como a oportunidade de construir um governo mais transparente e que represente, de fato, a população. A punição à corrupção no Brasil pode ser tornar uma influência para a América Latina, como proposto por alguns jornais.

\section{Considerações Finais}

A presente análise de conjuntura buscou identificar tendências de percepção internacional da crise brasileira a partir dos jornais da Argentina, Paraguai, Uruguai e Venezuela. Como é possível perceber, o desenrolar da crise política do Brasil tem sido uma questão de muita atenção por parte desses jornais. As recorrentes notícias sobre a temática com ênfase, sobretudo, no impeachment revelam os posicionamentos tomados por estes para a construção da opinião pública acerca do momento vivido no Brasil.

A análise também permitiu identificar continuidades e descontinuidades das percepções dos jornais com a política externa de cada país analisado. Nota-se como, em certo grau, as mídias acompanharam as diretrizes de política externa. Ora se opondo e ora apoiando o impeachment. Assim, os jornais, mesmo que sejam parte constituinte do componente doméstico, se apresentam também como uma ferramenta da política externa e relações internacionais, como sugerido por Putnam.

As percepções analisadas, portanto, mais do que tentar compreender a crise política brasileira, são um retrato deste período. No entanto, a percepção dos jornais é filtrada pelos interesses nacionais, ou mesmo particulares, de modo que a crise não seja entendida de forma homogênea por todos jornais. Assim, as interpretações são multifacetadas, o que revela mais sobre cada país analisado e suas relações com o Brasil, do que apenas deste. 
ABC COLOR. Nuevos tiempos para el Mercosur - Edicion Impresa - ABC Color. Disponível em: $<$ http://www.abc.com.py/edicion-impresa/politica/nuevos-tiempos-para-elmercosur-874263.html>. Acesso em: 6 out. 2016.

ADVIERTEN "resistencia" si avanza "golpe" a Rousseff. Hoy. Disponível em: $<$ http://www.hoy.com.py/mundo/advierten-que-resistencia-si-avanza-golpe-a-rousseff $>$. Acesso em: 15 maio. 2016.

BANCO MUNDIAL. Paraguay: panorama general. Disponível em: $<$ http://www.bancomundial.org/es/country/paraguay/overview $>$. Acesso em: 10 jun. 2016.

BATALLA "hasta el último minuto" por la Presidencia. Hoy. Disponível em: $<$ http://www.hoy.com.py/mundo/batalla-hasta-el-ultimo-minuto-por-la-presidencia $>$. Acesso em: 15 maio. 2016. a

BATALLA feroz para decidir destino de Rousseff - Internacionales. ABC Color. Disponível em: <http://www.abc.com.py/internacionales/batalla-feroz-para-decidir-destinode-rousseff-1470000.html>. Acesso em: 15 maio. 2016.

BRASILEÑOS continúan en las calles en rechazo al golpe. Correo del Orinoco. Disponível em: <http://www.correodelorinoco.gob.ve/multipolaridad/brasilenos-continuancalles-rechazo-al-golpe-fotos/>. Acesso em: 10 jun. 2016.

CANTELMI, M. La inquietante trampa que se puede construir en Brasil. Disponível em: $<$ http://www.clarin.com/mundo/inquietante-trampa-puede-construirBrasil_0_1559244277.html>. Acesso em: 15 maio. 2016.

CLAVES de una batalla. Clarín. Disponível em: $<$ http://www.clarin.com/mundo/Claves-batalla_0_1555644815.html $>$. Acesso em: 15 maio. 2016.

CUÉ, C. Argentina, el primer país en señalar que "respeta" el cambio en Brasil. Disponível

em: $<$ http://internacional.elpais.com/internacional/2016/05/12/actualidad/1463053399_1075 86.html>. Acesso em: 6 out.

DILMA Rousseff a un paso de la salida. El País. Disponível em: $<$ http://www.elpais.com.uy/mundo/dilma-rousseff-paso-salida-presidencia.html $>$. Acesso em: 10 jun. 2016a.

DILMA, la exguerrillera que lucha por su presidencia - Internacionales - ABC Color. Disponível em: <http://www.abc.com.py/internacionales/rousseff-la-exguerrillera- 
brasilena-que-lucha-por-salvar-su-presidencia-1469894.html>. Acesso em: 15 maio. $2016 b$.

DOS ERRORES de juicio que entorpecen el debate de la crisis. La Nación. Disponível em: <http://www.lanacion.com.ar/1885624-dos-errores-de-juicio-que-entorpecen-eldebate-de-la-crisis>. Acesso em: 15 maio. 2016.

EL CALVARIO del impeachment. El Observador. Disponível em: $<$ http://www.elobservador.com.uy/el-calvario-del-impeachment-n890903>. Acesso em: 10 jun. 2016.

EL FRENTE Amplio rechazó el golpe de Estado contra Rousseff. El Observador. Disponível em: <http:/www.elobservador.com.uy/el-frente-amplio-rechazo-el-golpeestado-contra-rousseff-n898505>. Acesso em: 15 maio. 2016.

EL GIGANTE suramericano está a la deriva - Internacionales - ABC Color. Disponível em: $\quad<$ http://www.abc.com.py/internacionales/brasil-el-gigante-suramericano-a-laderiva-1471637.html>. Acesso em: $15 \quad$ maio. 2016.

FALTA de representatividade política da população é abordada em evento da OAB. Disponível em: <http:/consultor-juridico.jusbrasil.com.br/noticias/232809961/falta-derepresentatividade-politica-da-populacao-e-abordada-em-evento-da-oab $>$. Acesso em: 6 out.

2016.

GALARZA, R. Brasil en su laberinto. El Observador. Disponível em: $<$ http://www.elobservador.com.uy/brasil-su-laberinto-n891261>. Acesso em: 15 maio. 2016.

GOMBATA, M. Você sabe o que é o bolivarianismo?. Carta Capital. Disponível em: $<$ http://www.cartacapital.com.br/politica/o-que-e-bolivarianismo-2305.html $>$. Acesso em: 10 jun. 2016.

GÓMEZ, L. Con la etiqueta \#ElMundoConDilma convocan a gran tuitazo este viernes | Correo del Orinoco. Disponível em: $<$ http://www.correodelorinoco.gob.ve/politica/etiqueta-elmundocondilma-convocan-agran-tuitazo-este-viernes/>. Acesso em: 10 jun. 2016.

GOSMAN, E. Dilma arremetió contra su vice: dijo que es "jefe de la conspiración". Disponível em: $\quad<$ http://www.clarin.com/mundo/Dilma-arremetio-vice-jefeconspiracion_0_1557444612.html $>$. Acesso em: 6 out. 2016.

LA NACION. La encrucijada brasileña. Disponível em: $<$ http://www.lanacion.com.ar/1890903-la-encrucijada-brasilena>. Acesso em: 6 out. 2016a.

LA NACION. Brasil, ante el juicio político a su presidenta. Disponível em: 
$<$ http://www.lanacion.com.ar/1899484-brasil-ante-el-juicio-politico-a-su-presidenta $>$. Acesso em: 22 set. 2016 b.

LARRETA, J. Argentina y Brasil. El País. Disponível em: $<\mathrm{http}$ //www.elpais.com.uy/opinion/argentina-brasil.html $>$. Acesso em: 15 maio. 2016.

LODOLA. G. Brasil abre una peligrosa caja de Pandora. La Nación. Disponível em: $<$ http://www.lanacion.com.ar/1892725-brasil-abre-una-peligrosa-caja-de-pandora $>$.

Acesso

em:

15

maio.

2016.

MADURO congela relações após "golpe oligárquico" no Brasil; EUA mantêm neutralidade. Disponível em: <http://noticias.uol.com.br/internacional/ultimasnoticias/2016/08/31/maduro-condena-golpe-oligarquico-da-direita-e-congela-relacoescom-o-brasil.htm>. $\quad$ Acesso em: $22 \quad$ set. 2016.

PUTNAM, R. Diplomacia e política doméstica: A lógica dos jogos de dois níveis. Revista de Sociologia e Política,Curitiba, v. 18, n. 36, p.147-174, jun. 2010. Disponível em: \&lt;http://www.scielo.br/pdf/rsocp/v18n36/10.pdf\&gt;. Acesso em: 22 set. 2016

VESTENA, C. O papel da mídia na formação da opinião pública: a contribuição de Bourdieu. Revista Guairacá, v. 1, n. 1, p. 9-22, 2011.

MINISTÉRIO DAS RELAÇÕES EXTERIORES. República Argentina. Disponível em: $<$ http://www.itamaraty.gov.br/pt-BR/ficha-pais/4785-republica-argentina $>$. Acesso em: 10 jun. 2016.

- República do Paraguai. Disponível em: <http://www.itamaraty.gov.br/ptBR/ficha-pais/5635-republica-do-paraguai>. Acesso em: 10 jun. 2016.

República Oriental do Uruguai. Disponível em: $<$ http://www.itamaraty.gov.br/pt-BR/ficha-pais/5417-republica-oriental-do-uruguai>. Acesso em: $10 \quad$ jun. 2016. MILNER, H.V. Introduction. In: MILNER (Ed.). Interests, institutions and information: domestic politics and international relations. Princeton: Princeton University Press, 1997 - pp.3-29.

MINISTÉRIO PÚBLICO FEDERAL. Entenda o caso - Caso Lava Jato. Disponível em: <http://lavajato.mpf.mp.br/entenda-o-caso $>$. Acesso em: 10 jun. 2016.

MIRANDA, T. Brasil exerce liderança instrumental e situacional na América do Sul AUN USP. Disponível em: <http://www.usp.br/aun/exibir.php?id=6213>. Acesso em: 10 jun. 2016.

MUROS, instalaciones y sobre todo mucho nerviosismo en Brasilia. La Nación. Disponível em: <http:/www.lanacion.com.ar/1888171-muros-instalaciones-y-sobre-todomucho-nerviosismo-en-brasilia>. Acesso em: 15 maio. 2016. 
NIELLA, R. Crisis políticas, causas morales. Abc Color. Disponível em: $<$ http://www.abc.com.py/edicion-impresa/opinion/crisis-politicas-causas-morales1471540.html>. Acesso em: 10 jun. 2016.

PAÍS que mais cresce nas Américas, Paraguai enfrenta desigualdade extrema. Brasil Econômico. Disponível em: <http://economia.ig.com.br/2013-05-04/pais-que-maiscresce-nas-americas-paraguai-enfrenta-desigualdade-extrema.html $>$. Acesso em: 10 jun. 2016.

PÉREZ-LINÃN, A. Brasil: es preciso repensar el juicio político. Clarín. Disponível em: $<$ http://www.clarin.com/opinion/Brasil-preciso-repensar-juiciopolitico_0_1564643616.html>. Acesso em: 10 jun. 2016.

. Dos errores de juicio que entorpecen el debate de la crisis. Clarín, Disponível em: $\quad<$ http://www.lanacion.com.ar/1885624-dos-errores-de-juicio-que-entorpecen-eldebate-de-la-crisis $>$. Acesso em: 10 jun. 2016.

PFEIFFER, A. Bajo la lupa, asusta la fragilidad de Brasil. Disponível em: $<$ http://www.lanacion.com.ar/1890654-bajo-la-lupa-asusta-la-fragilidad-de-brasil $>$.

$\begin{array}{lllll}\text { Acesso } & \mathrm{em}: & 18 & \text { set. }\end{array}$

URUGUAY, P. Gobierno de Uruguay se pronuncia sobre destitución de presidenta de Brasil, Dilma Rousseff - Presidencia de la República. Disponível em: $<$ https://www.presidencia.gub.uy/comunicacion/comunicacionnoticias/brasil-dilmacancilleria-comunicado>. Acesso em: 18 set. 2016.

RODRÍGUEZ, S. ¡Cuidado, la historia puede repetirse! (Análisis Internacional). Correo del Orinoco. Disponível em: $<$ http://www.correodelorinoco.gob.ve/nacionales/\%C2\%A1 cuidado-historia-puederepetirse-analisis-internacional/>. Acesso em: 10 jun. 2016.

SADER, E. Dilma o Temer Opinión. Correo del Orinoco. Disponível em: $<$ http://www.correodelorinoco.gob.ve/politica/dilma-o-temer-opinion>. Acesso em: 15 maio.

2016.

SIENRA, I. En Brasil no habrá golpe. El País. Disponível em: $<$ http://www.elpais.com.uy/opinion/brasil-no-habra-golpe.html $>$. Acesso em: 15 maio. 2016.

UNA PRESIDENTE enfrentada a sus propias limitaciones. La Nación. Disponível em: $<$ http://www.lanacion.com.ar/1890390-una-presidente-enfrentada-a-sus-propiaslimitaciones $>$. Acesso em: $\quad 15$ maio. 2016.

ZÁRATE, F. La crisis en Brasil, con efecto doble para la economía argentina. Disponível em: $\quad<$ http://www.ieco.clarin.com/economia/crisis-Brasil-efecto-economiaargentina_0_1534046793.html>. Acesso em: 6 out. 2016. 